Form io equations with special values for $\mathrm{a}$ and $\mathrm{b}$ and test by solving.

Second Type: $a x^{2}+b x+c=0$ gives

$$
x=\frac{-b+\sqrt{b^{2}-4 a c}}{2 a}
$$

The roots are (I) Real and Unequal, (2) Real and Equal, (3) Imaginary, (i.e., transverse) according as

$$
\mathrm{b}^{2} \stackrel{>}{=} 4 \mathrm{ac} .
$$

Polynomials in the Determinant Form.

$\left|\begin{array}{ll}a_{1}, & b_{1} \\ a_{2} & b_{2}\end{array}\right|=a_{1} b_{2}-a_{2} b_{1}$ is of the second order.

$\left|a_{1}, b_{1}, c_{1}\right|$

$a_{2}, b_{2}, c_{2}=a_{1} b_{2} c_{2}+a_{z} b_{5} c_{1}+a_{3} b_{1} c_{2}$

$a_{3}, b_{8}, c_{3} \mid-a_{1} b_{3} c_{2}-a_{2} b_{1} c_{3}-a_{3} b_{2} c_{1}$ of third order.

The science of these abbreviated forms is the Theory of Determinants.

All we need to observe here is that the first member denotes the algebraic sum of the products of three elements, one, and but one, being taken from each row and each column. The sign of a product is contrary to the slant of the ray of two of its elements.

$$
\begin{aligned}
& \left|\begin{array}{lll}
\mathrm{a}_{1}, & \mathrm{~b}_{2}, & \mathrm{c}_{2} \\
\mathrm{a}_{2}, & \mathrm{~b}_{2}, & \mathrm{c}_{2} \\
\mathrm{a}_{3}, & \mathrm{~b}_{3}, & c_{3}
\end{array}\right| \quad \text { IHI. }\left|\begin{array}{lll}
3, & 5,7 \\
4, & 2, & \mathrm{I} \\
\mathrm{I}, & \text { o, } & 7
\end{array}\right|=43 \\
& \begin{array}{r|c}
+ & - \\
42 & 14 \\
168 & 19 \\
5 & 140 \\
\hline 215- & 172 \cong 43
\end{array}
\end{aligned}
$$

(To be continued.)

\title{
A PECULIAR ACTION OF THE RADIOMETER.
}

$$
\text { By C. F. Adams, }
$$

Central High School, Detroit, Mich.

While arranging apparatus at one time to show selective absorption I happened to place a radiometer at the focus of light coming from the lantern so that the light was incident on the bright side of the vanes only. I was surprised to see it revolve in a direction opposite to the usual direction. Recently I repeated the experiment arranging the apparatus as shown in the figure in which $C$ represents the condenser of a lantern, $L$ an arc light, and $\mathrm{R}$ the radiometer. Two boards about $2 \mathrm{~cm}$ thick, were placed at $\mathrm{r} r$ with a space between them of about $\mathrm{I} \mathrm{cm}$. I had 
two flat bottles, one filled with water and the other with a very dark solution of iodine in carbon bisulphide. I shall call the bottle containing water, bottle No. I, and the other No. 2. B represents the position of a bottle when in use.

With no bottle in place the direction of rotation was as shown by the arrow, opposite to the usual direction. With bottle No. I

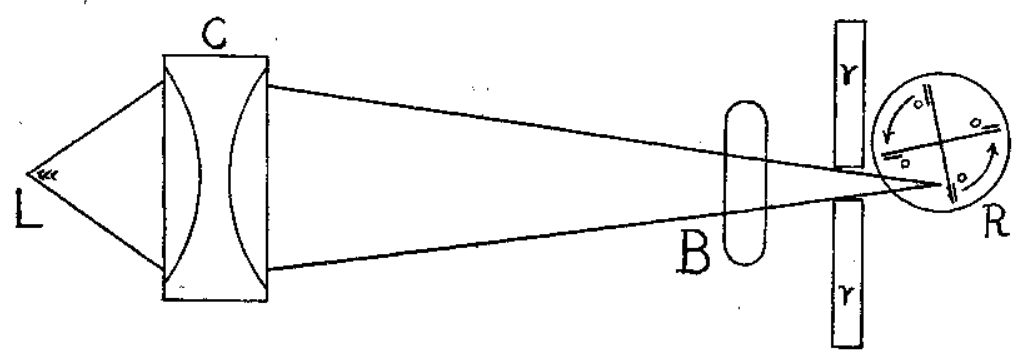

in place, when the greater part of the heat is cut off, the rotation is in the same direction as before and apparently at about the same rate. When bottle No. 2 is substituted for No. $\mathrm{r}$, the radiometer stops its rotation in the direction first given and turns in the opposite direction. In this case the heat at the radiometer is nearly as intense as when no bottle is in place. With both bottles in place, the direction of rotation is still the same as when no bottle is used, but very slow.

It is easy to see why the rotation is as described with no botthe in place. The radiation falls only on the bright surfaces of the vanes and hence those surfaces become warmer than the blackened surfaces; but why the rotation is reversed upon the interposition of bottle No. 2 , is not so easily explained. I have thought that perhaps it was due to fact that the long waves transmitted by the iodine solution passed through the mica of the vanes to the lampblack which absorbed them, so that the dark surfaces became warmer than the bright sides; but there are serious objections to this explanation. I have no other to offer, however. It may be that the phenomenon is one well known and has been explained, if so I am not aware of it.

One of the most comprehensive educational reports published in North America is that of October, 1905, by the Superintendent of Education of the Province of Nova Scotia. It is full of information which is useful to all teachers. It shows that the schools of this particular part of Canada are ably and well managed. The report recommends for the use of teachers School Science and Mathematics. 